\title{
A New Approach of Designing Superalloys for Low Density
}

\author{
R,A. MacKay, T.P. Gabb, J.L. Smialek, and M.V. Nathal
}

New low-density single-crystal (LDS) alloys have been developed for turbine blade applications, which have the potential for significant improvements in the thrust-to-weight ratio over current production supperalloys. An innovative alloying strategy was used to achieve alloy density reductions, hightemperature creep resistance, microstructural stability, and cyclic oxidation resistance. The alloy design relies on molybdenum as a potent, lowerdensity solid-solution strengthener in the nickel-based superalloy. Low alloy density was also achieved with modest thenium levels and the absence of tungsten. Microstructural, physical, mechanical, and environmental testing demonstrated the feasibility of this new $L D S$ superalloy design.

\section{INTRODUCTION}

The high-pressure turbine rotor is subjected to the most demanding conditions in the turbine engine and places a stringent set of requirements on the materials used in that application. The requirements for turbine blades include a balance of creep resistance, temperature capability, environmental resistance, and damage tolerance. Blade performance and durability are achieved through a combination of advanced alloys, sophisticated internal cooling schemes, and thermal barrier coatings.

Turbine blades have been made from nickel-based superalloy single crystals for thirty years. ${ }^{1}$ Alloy strength improvements have been achieved over the years by increasing the refractory element content and reducing the chromium content. The first generation of single-crystal superalloys contained 8-10 wt.\% chromium, 4-11 wt.\% tungsten, and no rhenium. Second-generation alloys typically contained $5-8 \mathrm{wt} . \%$
How would you...

...describe the overall significance of this paper?

A new alloy design strategy was used to develop single-crystal superalloys for turbine blade applications. The alloys developed demonstrate high creep strength, excellent cyclic oxidation resistance, acceptable hot corrosion resistance, and microstructural stability with a

lower alloy density compared with alloys currently used in turbine blade production. The alloys

Could lead to improvements in the thrust-to-weight ratio of the turbine engine, lowering fuel bum and decreasing harmful emissions.

-7...describe this work to a materials science and engineering professional with no experience in

27 your technical specialty?

Traditionally, creep strength

-7 improvements in superalloys have been achieved by increases in refractory metal content, especially

- dense elements such as rhenium and tungsten. The alloy design described henein used molybdenum as the main solid solution strengthener. Molybdenum has a density much closer to the nickel-alloy base than other refractory elements such as

El rhenium and tungsten. The designed alloy imparted a balance of properties needed for the demanding turbine engine environment.

...describe this work to a layperson?

Thrbine engine blades requine mechanical strength, high temperature capability, envimonmental resistance, and damage tolerance, since they are subjected to demanding conditions. Blade performance and durability are achieved through a combination of advanced alloys, sophisticated cooling schemes, and protective thermal barrier coatings. This paper discusses a design approach that provided alloys with properties requined for turbine blade applications. chromium, 5-8 wt.\% tungsten, and $3 \mathrm{wt} . \%$ thenium and have attained successful application in commercial and military aircraft engines. Third-generation alloys were designed to further increase the temperature capability and creep resistance by raising the rhenium levels up to $6 \mathrm{wt} . \%$ and lowering the chromium levels to $2-4$ wt.\%. Fourthgeneration alloys contain high levels of refractory metals (menium, tungsten, and tantalum) and low chromium levels, similar to those in the third-generation alloys, but distinguish themselves with the addition of ruthenium. These compositional changes over successive generations of alloys have brought about significant increases in creep strength along with concurrent increases in alloy density $^{2}$ and tendencies toward microstructural instabilities.

The phase instabilities observed after high-temperature exposures in some turbine blade alloys, especially those from the third and fourth generation, include topologically close-packed (TCP) phases and a secondary reaction zone (SRZ). ${ }^{3-1}$ The TCP phase is rich in refractory elements and is a discrete precipitate usually taking the form of a needle or plate. Although a small amount of TCP phase is tolerable, excessive quantities of TCP within the bulk of the superalloy are believed to decrease the creep rupture strength, especially long-term properties, by reducing the amount of refractory elements in solution in the gamma matrix. ${ }^{69-11}$ In contrast, SRZ is a three-phase instability and was first observed in the alloy substrate just beneath the diffusion zone of aluminide bondcoats. ${ }^{8}$ The SRZ is believed to severely decrease the mechanical properties $s^{3,4}$ by reducing the load-bearing cross section of the superalloy. 
Thus, the third- and fourth-generation alloys have some significant disadvantages, and a task was undertaken at NASA Glenn Research Center (GRC) to achieve improvements in the thrustto-weight ratio by reducing the density of a new alloy ${ }^{2}$ compared to second-generation alloys (such as Rene N5, SC180, CMSX-4, and PWA1484), which are widely used in turbine blade production. A decrease in the turbine blade weight has a potential cascading effect throughout the entire rotor (disk, hub, and shaft) and to non-rotating support structures, traditionally achieving a total engine weight savings of 8 to 10 times the blade weight savings. ${ }^{12}$ This blade weight savings and the total engine weight savings can be quite substantial because up to 100 turbine blades may be set on a turbine disk, with a number of disks per engine, and a number of engines per aircraft. Thus, because of the potential for significant impact in weight savings, the development of low-density, high-creepstrength single-crystal alloys was pursued for turbine blade applications.

See the sidebar for details on the alloy design strategy.

\section{LDS ALLOY CHEMISTRIES AND DENSITIES}

The analyzed chemistries of the three most creep resistant low-density singlecrystal (LDS) alloys (LDS-1101, LDS5555, and LDS-5051) are shown in Table I. These nickel-based alloys had variations in $\mathrm{Cr}$ from 2.4 to $4.7 \mathrm{wt}$.\%, Co from 0 to 9.9 wt.\%, Mo from 7.1 to $9.5 \mathrm{wt} \%$, and Re from 1.5 to $3 \mathrm{wt} . \%$, and contained baseline levels of 6.0 wt.\% Al, 6.2 wt.\% Ta, and 50 ppmw $Y$. The mean analyzed chemistries were within $0.3 \mathrm{wt} . \%$ of the desired levels of each main element, but more typically within $0.1 \mathrm{wt} . \%$. Thus, there was no particular difficulty in obtaining the aim chemistry targets for these singlecrystal alloy compositions. Boron and carbon were intentionally added at very low levels. Boron may combine with chromium or molybdenum to form borides which reside at grain boundaries, and carbon may combine with molybdenum or tantalum to form carbides. Borides and carbides can precipitate on undesirable grain boundaries that sometimes form in single crystals, and adding these interstitial elements in very small quantities has become a fairly standard practice in advanced single-crystal alloys. The analyzed sulfur content was $\sim 3$ to 4 ppmw, as measured by glow discharge mass spectroscopy at SHIVA Technologies. Considerable effort has been expended by superalloy manufacturers to reduce the sulfur in superalloy melts to levels below $10-20$ ppmw, ${ }^{9}$ and the LDS alloys have sulfur contents nearly an order of magnitude lower than this limit.

Densities of the LDS alloys were measured using the Archimedes meth$\operatorname{od}^{21}$ of water displacement. The densities of the LDS alloys with the strongest creep properties are plotted in Figure 1 and are compared to densities of various single-crystal alloys $\mathrm{s}^{3,6,7,9,22}$ from

\section{ALLOY DESIGN STRATEGY}

An alloying strategy was identified to achieve high-temperature creep resistance, alloy density reductions, microstructural stability, and cyclic oxidation resistance. The approach used in this alloy development effort was based upon research conducted on single-crystal alloys at NASA Glenn Research Center (GRC) in the $1980 \mathrm{~s},{ }^{13,14}$ although originally developed under Air Force sponsorship of the Rapid Solidified Processing Program. ${ }^{15,16}$ These nickel-based alloys were simple quaternary compositions that were rich in refractory metal, namely molybdenum. Molybdenum is a potent solid-solution strengthener, but has a density much closer to nickel than other refractory elements, such as rhenium and tungsten. The strongest alloys ${ }^{14}$ in this quaternary series actually had creep strengths slightly exceeding those of the third-generation alloy, CMSX-10, which demonstrated the potential of this alloy design strategy. Despite its significant creep strength and its low density of $\sim 8.4 \mathrm{~g} / \mathrm{cm}^{3}$, the quaternary alloy required significant compositional modifications to attain the desired balance of properties for turbine rotor applications. Thus, the challenge was to retain its exceptional creep strength and low density, while improving other desirable properties such as oxidation resistance.

A design of experiments approach was employed which minimized the number of alloys to be cast, while enabling good predictive capability of the properties of interest. The baseline alloy selected for this design strategy contained $6.1 \mathrm{wt} \% \mathrm{Al}, 12 \mathrm{wt} . \% \mathrm{Mo}$, $6.2 \mathrm{wt} . \% \mathrm{Ta}$, and a balance of $\mathrm{Ni}$. Elements were identified as being likely to improve the balance of properties of the baseline alloy, and included $\mathrm{Y}, \mathrm{Cr}, \mathrm{Re}$, and $\mathrm{Co}$. Yttrium was added for improved oxidation resistance, because it is believed to enhance the adherence of the protective oxide scales by gettering sulfur. ${ }^{17-19}$ Retained yttrium levels were targeted in the range of 50 to $100 \mathrm{ppmw}$. The remaining element levels were chosen so that the resultant matrix of alloys would likely contain a range of creep strength, oxidation resistance, and alloy stability. This range would allow for good predictive capabilities within the compositional design space, and if necessary, optimization experiments could be performed to achieve targeted property levels in subsequent casting rounds. Chromium was added to the alloy base for improved oxidation resistance with contents varied between 0 and $5 \mathrm{wt}$.\%. Rhenium was added at levels from 0 to $3 \mathrm{wt}$.\% because of its well-known effect of strengthening the gamma matrix and reducing gamma prime coarsening. It was desirable to avoid using ruthenium in these alloys, since it is considered an unconventional and expensive alloying element. Instead, cobalt was chosen since it is a more conventional elemental addition for superalloys, has a density that matches that of nickel, and is believed to improve alloy stability in a manner similar to that of ruthenium. ${ }^{3,5}$ The cobalt levels ranged from 0 to $10 \mathrm{wt} . \%$. With all of these compositional changes made to the baseline quaternary alloy, the molybdenum level would also need to be optimized. The molybdenum level was varied from 7 to $12 \mathrm{wt} . \%$, and it is this high molybdenum range, in conjunction with the relatively low chromium content, that makes this alloy design unique. A patent has been awarded for this alloy design. ${ }^{20}$

A preliminary round of 12 alloys was cast at GRC in polycrystalline form by vacuum induction melting. This casting method provided an inexpensive way to obtain initial screening data and guidance for the subsequent single-crystal casting round. Statistical models were developed and used to downselect to seven alloys for casting in single crystal form at a commercial vendor. Density measurements, microstructural stability assessments, and creep rupture, cyclic oxidation, and hot corrosion testing were performed on these seven alloys. ${ }^{2}$ Because of the creep rupture properties, oxidation resistance, and density levels achieved, feasibility has been demonstrated for this lowdensity single-crystal (LDS) superalloy design. The remainder of this paper will provide an overview of the LDS single-crystal alloys (LDS-1101, LDS-5555, and LDS-5051) which have shown the best balance of properties. 
Table I. Analyzed Compositlons (wt.\%) of Single Crystal Alloys

\begin{tabular}{|c|c|c|c|c|c|c|c|c|c|c|c|}
\hline Alloy & Al & Cr & Co & Mo & Re & Ta & $\underset{\text { (ppmw)* }}{\mathbf{Y}}$ & NI & B & C & $\underset{\text { (ppmw) }}{\mathbf{S}}$ \\
\hline LDS-1101 & 6.0 & 4.7 & 9.9 & 7.1 & 3.0 & 6.2 & 50 & 63.1 & 0.0035 & 0.0160 & 4.1 \\
\hline LDS-5555 & 6.0 & 2.4 & 4.9 & 9.5 & 1.5 & 6.2 & 46 & 69.4 & 0.0032 & 0.0168 & 2.8 \\
\hline LDS-5051 & 6.0 & 2.4 & 0.0 & 9.0 & 3.0 & 6.1 & 65 & 73.4 & 0.0040 & 0.0140 & 2.8 \\
\hline
\end{tabular}

" ppm by weight from top of casting

first through fourth generations. The LDS alloys had densities lower than those of fourth-generation EPM102, third generation CMSX-10Ri, and second-generation alloys PWA1484, SC180, CMSX-4, and Rene N5. It is noteworthy that two of the three LDS alloys also had densities lower than that of first-generation Rene N4. The significantly lower densities of the LDS alloys is the result of the use of a high level of molybdenum as a strengthening element, the low level of rhenium, the absence of tungsten, the useful range of cobalt, and the lower tantalum content. Thus, the alloy design was a success with regard to decreasing density relative to that of commercial alloys used in production of single-crystal turbine blades.

\section{CREEP RUPTURE STRENGTH}

Creep rupture testing of the LDS single crystals was conducted in air at $982^{\circ} \mathrm{C}$ and $1,038^{\circ} \mathrm{C}$ at GRC according to ASTM-E $139-06 ;{ }^{23}$ two applied stress levels were used at each temperature. Prior to machining the creep rupture specimens, the single-crystal slabs were given a simulated coating cycle plus an age at $1,079^{\circ} \mathrm{C}$ in argon for $4 \mathrm{~h}$, argon gas quenched to below $871^{\circ} \mathrm{C}$, aged at $871^{\circ} \mathrm{C}$ for $12 \mathrm{~h}$, and finally argon quenched to ambient temperature. LDS-1101, LDS-5555, and LDS-5051 were consistently the strongest alloys in the first round of castings. LDS-1101 had the longest creep rupture lives at $982^{\circ} \mathrm{C}$ at both applied stress levels, whereas LDS-5555 was stronger in creep at $1,093^{\circ} \mathrm{C}$ at the lower stress level of $110 \mathrm{MPa}$. LDS-1101, LDS-5555, and LDS-5051 had equivalent lives at $1,093^{\circ} \mathrm{C}$ and $124 \mathrm{MPa}$. Similar alloy trends were observed for times to $1 \%$ and $2 \%$ creep strain.

The creep strengths of different alloys are often compared using a Larson Miller Parameter (LMP) plot, which en- ables direct comparison between alloys that were creep tested under different conditions. With the LMP curves generated for two different alloys, a creep life advantage can be calculated for a given temperature and stress; or alternatively, as is often done for turbine blade materials, a temperature advantage can be calculated for one material over another at a given life and applied stress.

A series of LMP plots in Figures 2 through 4 demonstrate several advantages of LDS-1101, LDS-5555, and LDS-5051 over second, third, and fourth generation single-crystal superalloys. Figure 2 shows that LDS-1101 has a very significant $22^{\circ} \mathrm{C}$ to $40^{\circ} \mathrm{C}$ temperature advantage over Rene $\mathrm{N}^{6}$ for a wide range of applied stresses. The biggest improvements observed for LDS-1101 were at the lower applied
Figure 2. A Larson Miller Parameter plot for three lowdensity single-crystal (LDS) superalloys. Comparison to Rene $\mathrm{N5}^{\circ}$ is provided. LDS-1101 has up to a $40^{\circ} \mathrm{C}$ temperature advantage over Rene N5. stress levels used during creep testing at $1,093^{\circ} \mathrm{C}$. LDS-5555 and LDS-5051 exhibited creep strengths similar to those of Rene N5 at the higher stress levels, but also had significant temperature advantages over Rene N5 at the lower stress levels. Since these three LDS alloys also have slightly lower densities than Rene N5 (Figure 1), the temperature advantage of the LDS alloys would be increased further if the applied stress was corrected for density.

Favorable comparisons of the LDS alloys to third- and fourth-generation alloys have also been demonstrated. Figure 3 shows the creep strength of the LDS alloys relative to third generation alloys Rene $N 6^{6}$ and CMSX-10 $\mathrm{Ri}^{24}$ and to fourth generation EPM102.3.5 It is noteworthy that there is significant overlap for these alloys over a wide range in the LMP curves, although a few differences are evident. At stress levels above $\sim 210 \mathrm{MPa}$, Rene N6 has more favorable creep strength relative to the LDS alloys. Above $170 \mathrm{MPa}$, EPM102 and CMSX-10Ri have improved creep strengths over the LDS alloys and Rene N6. However, below 170 $\mathrm{MPa}$, the creep data for all of these al-

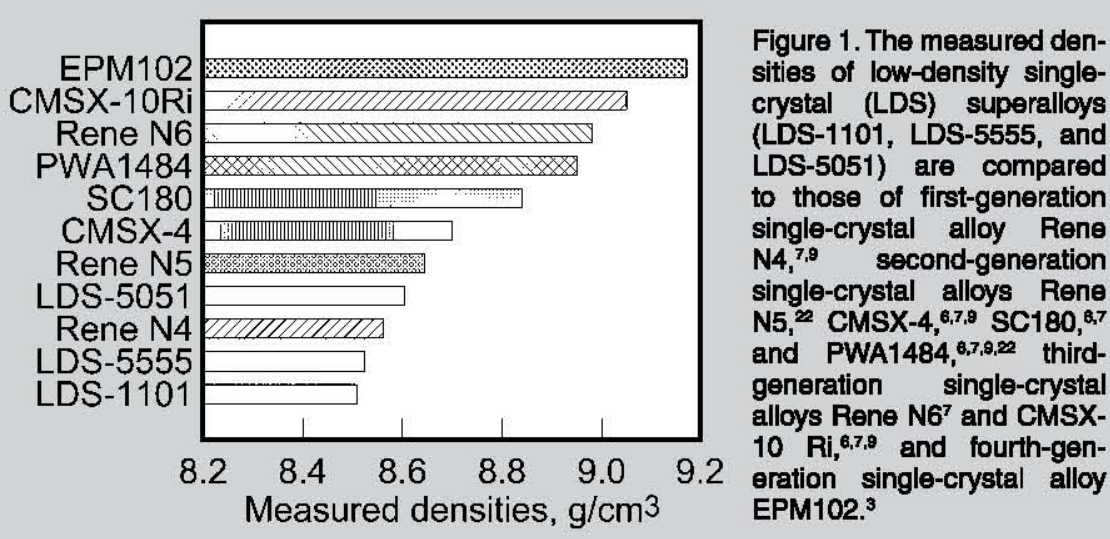

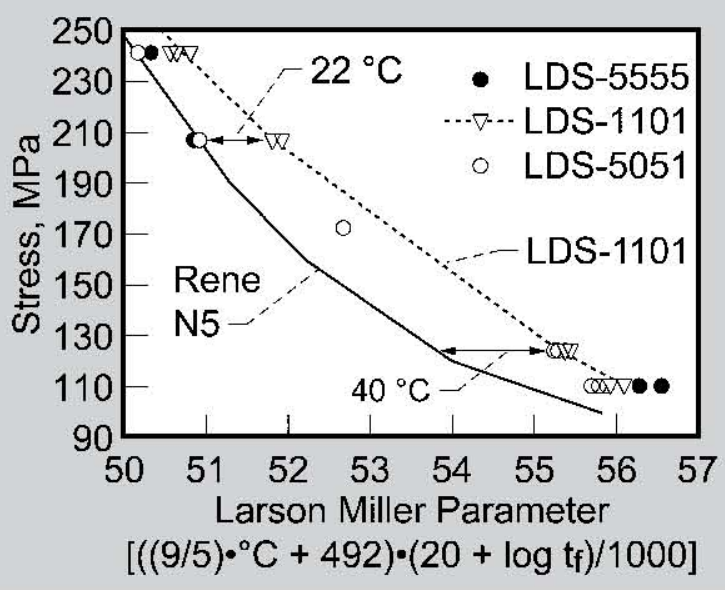




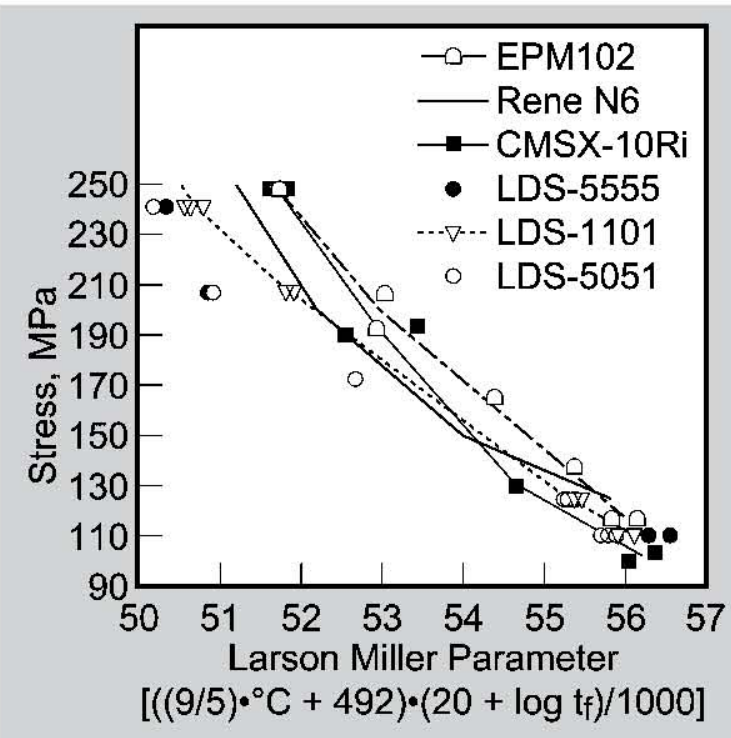

Figure 3. A Larson Miller Parameter plot for low-density single-crystal (LDS) superalloys. Comparison to EPM102, ${ }^{3.5}$ Rene N6, ${ }^{6}$ and CMSX-10 $\mathrm{Ri}^{24}$ is provided. loys converge, and the LDS alloys have rupture strengths that are very similar to both third and fourth generation alloys. This similarity in creep life at a testing temperature of $1,093^{\circ} \mathrm{C}$ may be partially attributed to the long-term microstructural stability of alloys such as LDS-1101 and LDS-5555, and will be examined in more detail in future studies.

The densities of the LDS alloys are 6 to $7 \%$ lower than EPM 102 and 5 to 6\% lower than CMSX-10Ri. When alloy density is taken into account, the LDS alloys have normalized creep strengths that are very similar to fourth generation EPM102 over a wide range of stresses (Figure 4). Furthermore, the LDS alloys exceed the density-compensated creep strength of CMSX-10Ri in the low stress range and provide up to a $20^{\circ} \mathrm{C}$ temperature advantage over CMSX-10Ri. Thus, the LDS alloys provide their greatest potential benefits at low stress/high-temperature creep conditions. Coupling these significant creep property advantages with a density reduction has the potential of providing a reduced overall vehicle system weight, greater fuel efficiency, and reduced emissions.

\section{MICROSTRUCTURAL STABILITY}

The LDS alloys were aged isothermally at $982^{\circ} \mathrm{C}$ and $1,093^{\circ} \mathrm{C}$ in argon for $200 \mathrm{~h}$ and $500 \mathrm{~h}$ to determine microstructural stability. Figure 5 shows microstructures after $500 \mathrm{~h}$ of aging at $1,093^{\circ} \mathrm{C}$ for LDS-1101, LDS-5555, and LDS-5051. Two alloys, LDS-1101 and LDS-5555, exhibited a low volume fraction of TCP laths after $500 \mathrm{~h}$ of aging (Figure 5a and b). Similar TCP morphologies and quantities were observed in these alloys after creep testing. Significantly higher quantities of TCP phase were present in LDS-5051 (Figure 5c) after the same aging exposure.

Quantitative measurements of the TCP phase in the LDS alloys were obtained using image analysis software after aging exposures and after creep rupture testing. LDS-1101 and LDS5555 had TCP phase contents that were $<0.6 \mathrm{vol} . \%$ after $500 \mathrm{~h}$ or more at either $982^{\circ} \mathrm{C}$ or $1,093^{\circ} \mathrm{C}$. Alloys with $\leq 1$ vol.\% TCP phase content are generally considered to be stable alloys. It is interesting to note that LDS-1101 and
LDS-5555 were the two strongest LDS alloys in creep in this round of alloys. Although a number of factors affect creep properties, it appears that LDS1101 and LDS-5555 have acceptable TCP phase stability limits for exceptional creep strength.

In contrast, LDS-5051 precipitated significant quantities of TCP phase after $500 \mathrm{~h}$ of aging, with mean contents of 6 vol. $\%$ at $982^{\circ} \mathrm{C}$ and 4 vol. $\%$ at $1,093^{\circ} \mathrm{C}$. LDS-5051 appeared to have reached its equilibrium TCP phase content during exposure at $982^{\circ} \mathrm{C}$. However, the kinetics for TCP phase precipitation were slower for LDS-5051 at $1,093^{\circ} \mathrm{C}$, since its TCP phase content appeared to be increasing linearly through $500 \mathrm{~h}$ of exposure. It should be noted that LDS5051 was one of the more creep resistant alloys in this round of alloys, despite its relatively high TCP phase content. This may suggest that the creep resistance of single-crystal alloys may be more tolerant of the presence of TCP phase than previously thought, although the impact of TCP laths on fatigue properties also needs to be examined.

\section{CYCLIC OXIDATION}

Cyclic oxidation tests were performed on the LDS alloys and selected commercial alloys at $1,100^{\circ} \mathrm{C}$ and $1,150^{\circ} \mathrm{C}$ for 200 cycles in air. Each cycle consisted of a $1 \mathrm{~h}$ hold at either $1,100^{\circ} \mathrm{C}$ or $1,150^{\circ} \mathrm{C}$, followed by a $10-\mathrm{min}$. cool. At numerous intervals throughout the oxidation tests, weight changes were measured, and samples were visually examined for scale phases and general
Figure 4. A Larson Miller Parameter plot for three lowdensity single-crystal (LDS) superalloys with density normalization made for EPM102, CMSX-10Ri, and Rene N6. The creep strength data collapse significantly when alloy density is taken into account.

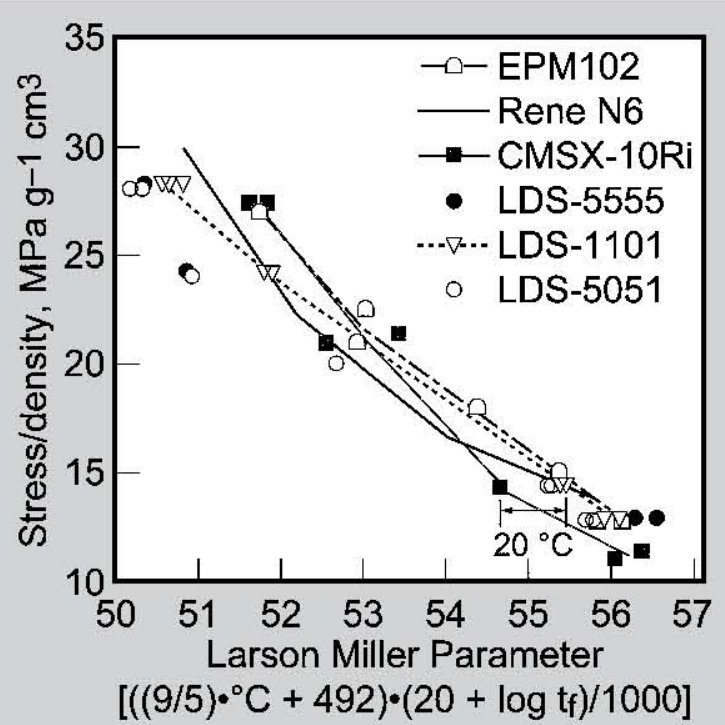


scale adherence. The results for LDS1101, LDS-5555, and LDS-5051 will be presented here. These LDS alloys contained $\sim 50$ ppmw yttrium, which was added specifically to enhance cyclic oxidation resistance by gettering sulfur and improving oxide scale adherence. These alloys also contained $6.0 \mathrm{wt} . \%$ aluminum, which was in the same range as that in the most oxidation-resistant single-crystal alloys. In general, chromium was the element within the LDS design space that was most influential to oxidation behavior. ${ }^{2}$

Figure 6 compares the $1,100^{\circ} \mathrm{C}$ cyclic oxidation data for the $5 \mathrm{wt}$.\% chromium LDS alloy (LDS-1101), the $2.5 \mathrm{wt} . \%$ chromium LDS alloys (LDS-5555 and LDS-5051), second-generation single-

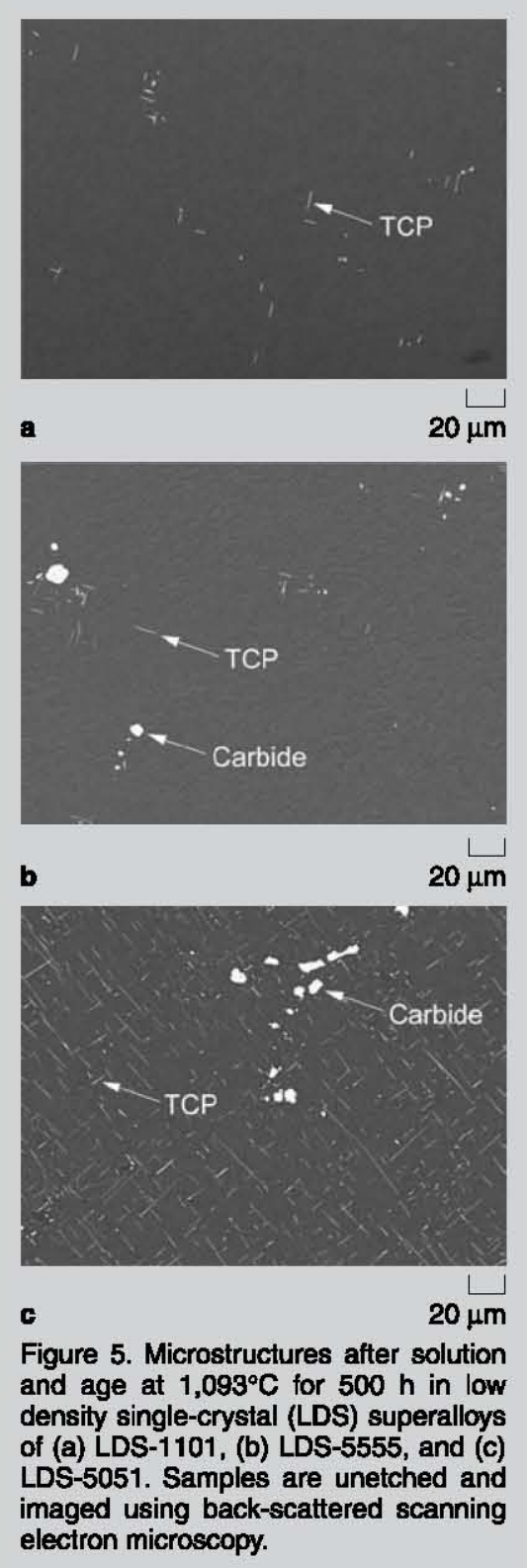

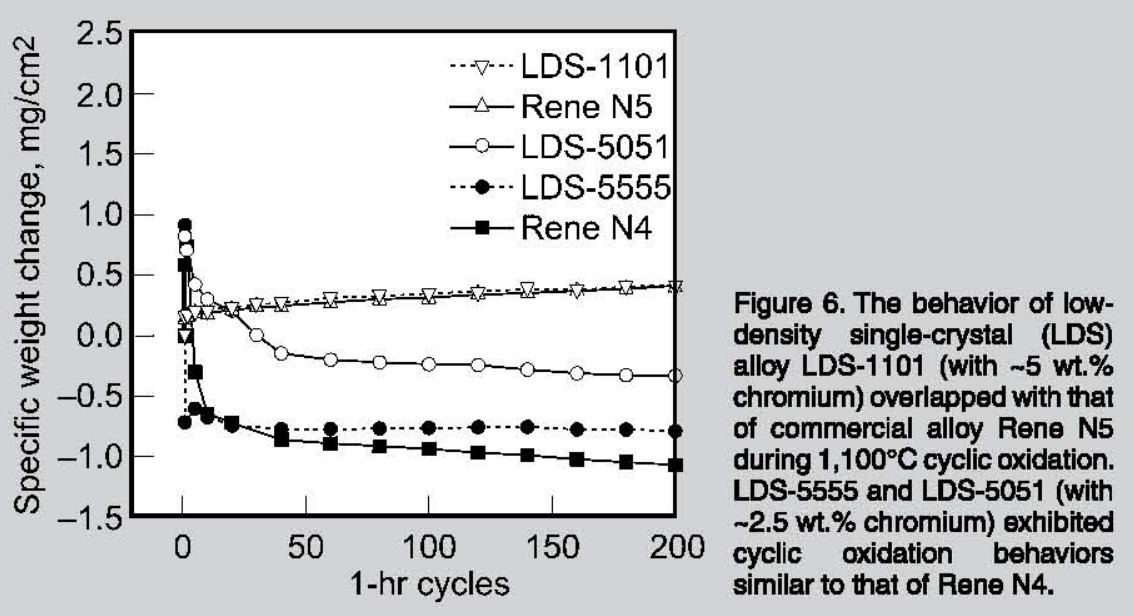

crystal alloy Rene N5, and first-generation single-crystal alloy Rene N4. The similarity in oxidation behavior between LDS-1101 and the highly oxidation-resistant Rene N5 is quite apparent throughout the 200 cycle test. The LDS-1101 and Rene N5 data overlapped, exhibiting small positive weight gains of less than $0.4 \mathrm{mg} / \mathrm{cm}^{2}$ through 200 cycles. Small positive weight gains are considered beneficial because this suggests that adherent, protective scales are developing on the test coupons. After 200 cycles, the oxidation sample of LDS-1101 was dominated by an adherent, gray surface oxide; blue oxides were present in only a few localized spots, primarily at sample edges. These oxide colors are characteristic of a protective alumina healing layer and spinel transients, respectively.

The LDS alloys with $2.5 \mathrm{wt}$.\% chromium (LDS-5555 and LDS-5051) exhibited rapid, initial weight gains of about $1 \mathrm{mg} / \mathrm{cm}^{2}$ followed by early weight losses and then relatively little weight change after 50 cycles. This behavior was likely an initial growth and spallation transient followed by a form of rapid healing, which was supported by the macroscopic scale observations. The cyclic oxidation behaviors of LDS5555 and LDS-5051 were very similar to that of Rene N4, Figure 6. A level of only $2.5 \mathrm{wt}$.\% chromium appeared insufficient to provide optimal oxidation resistance. ${ }^{2}$ These results were not particularly surprising since increased chromium content in superalloys has been weakly correlated with improved cyclic oxidation resistance, although this typically occurs at levels higher than 5 wt.\%.17
The phases in the oxide scales were identified by $x$-ray diffraction after the completion of 200 cycles of cyclic oxidation testing at $1,100^{\circ} \mathrm{C}$. Alumina $\left(\alpha-\mathrm{Al}_{2} \mathrm{O}_{3}\right)$ was identified as a prominent primary scale phase only in LDS-1101, and was present, at most, as a minor phase in the $2.5 \mathrm{wt}$. \% chromium alloys. However, spinel $\left[(\mathrm{Ni}, \mathrm{Co})(\mathrm{Al}, \mathrm{Cr})_{2} \mathrm{O}_{4}\right]$ and $\mathrm{CrTaO}_{4} / \mathrm{NiTa}_{2} \mathrm{O}_{6}$ were also promiloys. NiO was not present on LDS-1101 but was present to varying degrees on LDS-5555 and LDS-5051. Presumably, spinel, $\mathrm{CrTaO}_{4} / \mathrm{NiTa}_{2} \mathrm{O}_{6}$, and $\mathrm{NiO}$ reflect rapid transient oxidation for alloys that are borderline alumina formers, until a healing $\mathrm{Al}_{2} \mathrm{O}_{3}$ layer is established at the oxide-metal interface. $\mathrm{CrTaO}_{4} / \mathrm{NiTa}_{2} \mathrm{O}_{6}$ is commonly observed on superalloys and may be playing a role in preventing excessive and persistent $\mathrm{NiO}$ growth. Careful examination of oxide-substrate cross sections and surface microstructures is planned to more fully understand the roles of the various phases that are present in these oxide scales.

Selected cyclic oxidation tests were also performed at $1,150^{\circ} \mathrm{C}$. LDS-1101 exhibited small, positive weight gains over 200 cycles at $1,150^{\circ} \mathrm{C},{ }^{2}$ and looked promising relative to Rene $\mathrm{N} 5^{25}$ up to 200 cycles. LDS-5051 exhibited similar initial weight gains at $1,150^{\circ} \mathrm{C}$ and $1,100^{\circ} \mathrm{C}$, but its rate of subsequent weight loss at $1,150^{\circ} \mathrm{C}$ was higher than that at $1,100^{\circ} \mathrm{C}$.

Based on these cyclic oxidation tests and others, ${ }^{2}$ molybdenum levels between 7 and $12 \mathrm{wt} \%$ are tolerable with respect to cyclic oxidation in the presence of $\sim 5 \mathrm{wt} . \%$ chromium. Molybdenum is generally thought to be nent in the scales on all of these LDS al- 
particularly detrimental to oxidation resistance. Thus, it is remarkable that an alloy, such as LDS-1101, with $4.7 \mathrm{wt}$.\% $\mathrm{Cr}, 6.0 \mathrm{wt} \% \mathrm{Al}, 50 \mathrm{ppmw} \mathrm{Y}$, and 7.1 wt.\% Mo has a cyclic oxidation behavior similar to that of second-generation alloy Rene N5, which possesses excellent oxidation resistance. Furthermore, these results indicate that a chromium level near $5 \mathrm{wt} \%$ is crucial in this alloy design for optimal cyclic oxidation resistance. Increasing the chromium content to still higher levels might provide further improvements in the cyclic oxidation resistance for these alloys. However, chromium levels greater than $5 \mathrm{wt} . \%$ are expected to compromise the creep rupture strength, so a trade-off in properties is likely. The effect of cobalt is not straightforward, as it appears to be neutral or beneficial; future regression modeling of all the LDS alloys cast and tested may help to pinpoint this and other compositional effects.

\section{HOT SALT CORROSION}

Cyclic hot salt corrosion testing was conducted in a Mach 0.3 burner rig on LDS-1101, a series of commercial single-crystal superalloys (Rene N5, CMSX-4, and CMSX-10Ri), and fourth-generation single-crystal alloy EPM102. Test conditions included a $1 \mathrm{~h}$ heating cycle to $900^{\circ} \mathrm{C}$ followed by a 5 to $10 \mathrm{~min}$. cooling cycle; $2 \mathrm{ppm}$ sea salt was applied during the full heating cycle. The hot corrosion pins of these alloys remained cylindrical with a minor amount of discoloration in the burner rig flame impingement area. Figure 7 shows the cyclic hot corrosion weight change data through 200 cycles. Except

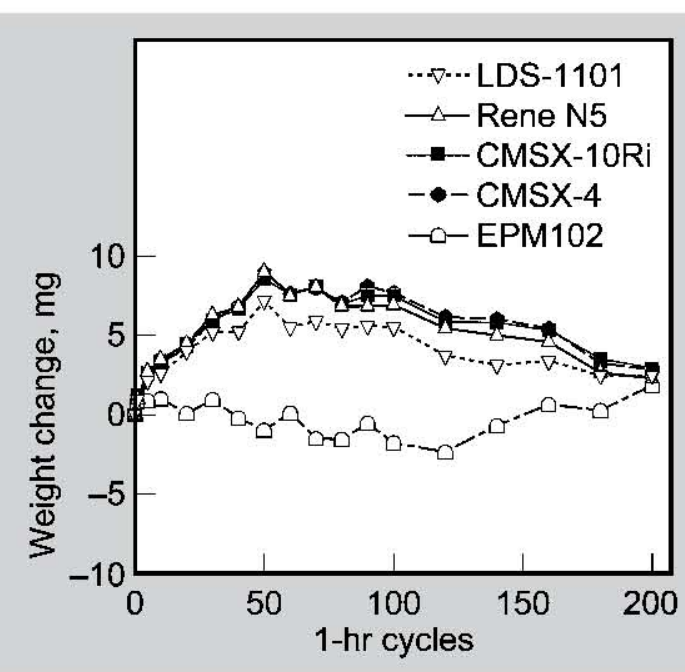

for EPM102, the commercial alloys and LDS-1101 all followed the same trends with small weight gains during the first 50 cycles and very small, gradual weight losses over the next 150 cycles. The same small perturbations in the curves were observed between these commercial alloys and LDS-1101, which may reflect some subtle change during testing with respect to salt deposition rate, salt dispersion, or perhaps coking. LDS-5555 and LDS-5051 exhibited 10-20 mg weight gains during the first 50 cycles but then exhibited breakaway behavior.

Although weight change is used as one of the most straightforward indicators of hot corrosion resistance, detailed chemical analyses of soluble deposits, metallographic cross sections, and $x$ ray diffraction are needed for examination of surface and internal layers to verify the hot corrosion behavior. Additional testing through 500 cycles will also be pursued to determine if these alloy trends continue. Nevertheless, LDS-1101 exhibited hot corrosion behavior which approached that of the commercial alloys Rene N5, CMSX-4, and CMSX-10Ri through 200 cycles; these alloys had chromium levels ranging from 2 to $7 \mathrm{wt} . \%$.

\section{CONCLUSION}

The challenge for co-optimizing stability, creep resistance, density, and cyclic oxidation in this unique superalloy design space has been achieved. LDS-1101 (with 4.7 wt.\% Cr, 9.9 wt.\% $\mathrm{Co}, 7.1 \mathrm{wt} . \% \mathrm{Mo}$, and $3 \mathrm{wt} . \%$ rhenium) has the best balance of properties and brings together the best attributes of three generations of single-crystal alloys with: a creep strength exceeding that of third generation single-crystal alloys at low applied stresses and temperatures near $1,100^{\circ} \mathrm{C}$; an oxidation resistance approaching that of the most oxidation-resistant second-generation alloy; and a low density similar to that of first-generation single-crystal alloys. The most creep-resistant LDS alloys had TCP phase contents that were less than 0.6 vol.\%. However, LDS-5051 was also highly creep resistant despite precipitating up to 6 vol.\% TCP phase. This may suggest that single-crystal alloys may be more tolerant of TCP phases during creep rupture than previously thought, although the impact of TCP laths on fatigue properties also needs to be examined.

LDS-1101 was a strong alumina former and exhibited cyclic oxidation behavior like that of the most oxidationresistant, second-generation singlecrystal alloy. Although cyclic oxidation in furnaces has been a cost effective and highly reliable tool for screening, burner rig oxidation tests are planned since they provide a more realistic environment for turbine engine applications. The reasonably good performance of LDS-1101 in hot salt corrosion was unexpected because molybdenum had long been associated with poor hot corrosion resistance. It also appears that $5 \mathrm{wt} . \%$ chromium is needed, but is not sufficient, for hot corrosion resistance in this design space.

Optimization studies have begun within LDS compositional space, centering around the LDS-1101 alloy, where small modifications to its composition were made. Testing is in progress, and regression models will be developed and compared to available software packages for predicting superalloy behavior. The alloy design allows for further reductions in rhenium levels, which would not only further reduce alloy density, but would provide less dependence on the rare and expensive rhenium.

Figure 7. The low-density singlecrystal (LDS) superalloy LDS1101 follows similar trends in hot corrosion behavior to the commercial alloys shown during testing in Mach 0.3 cyclic hot salt corrosion at $900^{\circ} \mathrm{C}$. Weight change of EPM102 does not follow the pattern of other alloys.

\section{ACKNOWLEDGEMENTS}

The authors wish to acknowledge Dr. Ram Darolia, formerly of General Electric Aircraft Engines, for supply of Rene N5 for oxidation and hot corrosion testing. 


\section{References}

1. M. Gell, D.N. Duhl, and A.F. Giamei, Superalloys 1980, ed. J.K. Tien et al. (Metals Park, OH: American Society for Metals, 1980), pp. 205-214.

2. R.A. MacKay ot al., "Alloy Design Challenge: Development of Low Density Superalloys for Turbine Blade Applications," NASA TM-2009-215819 (Washington, D.C.: NASA, 2009), http://gitrs.grc nasa.gov/Citations.aspx?ID=4661.

3. Enabling Propulsion Materials Program: Final Technical Report, Volume 4, Task J - Long-Life Turbine Airfoil Materials System, 01 October 1998 to 31 October 1999, NASA Contract NAS 3-26385 (May 2000).

4. R.A. MacKay et al., "Assessment of Creep Capability of HSR-EPM Turbine Airtoil Alloys," NASA TM-2007214921 (Washington, D.C.: NASA, 2007).

5. S. Walston et al., Superalloys 2004, ed. K.A. Green et al. (Warrendale, PA: TMS, 2004), pp. 15-24. Also NASATM-2004-213062.

6. W.S. Walston ot al., Superalloys 1996, ed. R.D. Kissinger et al. (Warrendale, PA: TMS, 1996), pp. 27-34.

7. G.L. Erickson, in Ref. 6, pp. 35-44.

8. W.S. Walston, J.C. Schaeffer, and W.H. Murphy, in Ref. 6, pp. 9-18.

9. R.C. Reed, The Superalloys: Fundamentals and Applications (Cambridge, U.K.: Cambridge University
Press, 2006), pp. 148-170.

10. D.N. Duhl, Alloy Phase Stability and Design, vol. 186, ed. G.M. Stocks, D.P. Pope, and A.F. Giamei (Pittsburgh, PA: MRS, 1991), pp. 389-400.

11. W.S. Walston, Long Term Stability of High Temperature Materials, ed. G.E. Fuchs, K.A. Dannemann, and T.C. Deragon (Warrendale, PA: TMS, 1999), pp. 43-53.

12. H.R. Gray, NASA Glenn Research Center, private communication with first author (September 2001).

13. R.A. MacKay and LJ. Ebert, Superalloys 1984, ed. M. Gell et al. (Warrendale, PA: TMS, 1984), pp. 135-144.

14. R.A. MacKay, M.V. Nathal, and D.D. Pearson, Metall. Trans. A, 21A (1990), pp. 381-388.

15. A. Cox et al., DARPA Contract F33615-76-C-5136 (1979).

16. P.L. Martin, H.A. Lipsitt, and J.C. Williams, Proc Second Intl. Conf on Rapid Solidification Processing, ed. R. Mehrabian, B.H. Kear and M. Cohen (Baton Rouge, LA: Claitor's Publishing Division, 1980), pp. 123-128.

17. J.L. Smialek, C.A. Barrett, and J.C. Schaeffer, ASM Handbook: Materials Selection and Design, vol. 20 (Materials Park, OH: ASM International, 1997), pp. 589-602.

18. J.L. Smialek and R. Browning, Electrochemical Society Symposium Proceedings on High Temperature Materials Chemistry III (Pennington, NJ:
Electrochemical Society, 1986), pp. 259-271.

19. J.G. Smeggil, A.W. Funkenbusch, and N.S. Bornstein, Motall. Trans. A, 17A (1986), pp. 923-982. 20. R.A. MacKay ot al., U.S. patent 7,261,783 B1 (28 August 2007).

21. Mettler Density Determination Kit ME-40290, Mettler Instrument Corporation, Hightstown, NJ, 1981, pp. 1-5.

22. Enabling Propulsion Materials Program: Annual Technical Progress Report, Volume 3, Task C - Other Critical Components, 1 January 1993 - 31 December 1998, NASA Contract NAS3-26385, January 1994.

23. ASTM Designation: E139-06, "Standard Test Methods for Conducting Creep, Creep-Rupture, and Stress-Rupture Tests of Metallic Materials," in Volume 3.01 Metals - Mechanical Testing: Elevated and LowTemperature Tests: Metallography, 2006 Annual Book of ASTM Standards (West Conshohocken, PA: ASTM International, 2006), pp. 318-331.

24. G.L.Erickson, U.S. patent 5,366,695 (22 November 1994).

25. J.L. Smialek and B.A. Pint, "Optimizing Scale Adhesion on Single Crystal Superalloys," NASATM2000-210362 (Washington, DC: NASA, 2000).

R.A. MacKay, T.P. Gabb, J.L. Smlalek, and M.V. Nathal are with the NASA Glenn Research Center, Cleveland, OH 44135. Dr. MacKay can be reached at rebecca.a.mackayenasa.gov. 